\title{
PENGARUH BERBAGAI DOSIS PUPUK KOMPOS TANDAN KOSONG KELAPA SAWIT PLUS (KOTAKPLUS) DALAM MEMPERBAIKI SIFAT KIMIA TANAH ULTISOL
}

\author{
A.HAITAMI ${ }^{1 *}$, dan WAHYUDI ${ }^{1}$ \\ ${ }^{1}$ Program Studi Agroteknologi Fakultas Pertanian \\ Universitas Islam Kuantan Singingi \\ *Email : haitami1982@gmail.com
}

\begin{abstract}
ABSTRAK
Penelitian ini adalah bertujuan untuk mengetahui kandungan unsur hara pupuk kompos tandan kosong kelapa sawit plus (KOTAKPLUS). dan dosis pupuk kompos tandan kosong kelapa sawit plus (KOTAKPLUS) yang terbaik dalam memperbaiki sifat kimia tanah pada tanah ultisol. Penelitian dilakukan selama tujuh bulan yaitu dimulai pada fase pertama pada bulan Februari 2018 yaitu pembuatan pupuk kompos tandan kosong kelapa sawit plus (KOTAKPLUS) dan pupuk kompos TKKS saja. Kemudian pada fase Kedua dimulai pada bulan April 2018 yaitu lama inkubasi kompos. Data yang diperoleh dari perlakuan yang diuji diambil berdasarkan metode random sampling. Lama inkubasi pupuk kompos KOTAKPLUS terdiri dari lima taraf perlakuan dan tiga ulangan, yaitu : $\mathrm{A}=$ Tanpa Perlakuan (Kontrol), B =KOTAKPLUS 10 ton ha ${ }^{-1}, \mathrm{C}=$ KOTAKPLUS 20 ton ha ${ }^{-1}, \mathrm{D}=$ KOTAKPLUS 30 ton ha ${ }^{-1}$, dan $\mathrm{E}=$ Kompos TKKS saja. Berdasarkan hasil penelitian dan analisis dari laboratorium yang sudah dilaksanakan dapat diambil kesimpulan bahwa kompos KOTAKPLUS memiliki nilai pH yaitu 10,1, COrganik 21,06 \%, N sebesar 0,94 \%, P sebesar 2,19\%, K sebesar 2,94 \%, Ca sebesar 6,24 \%, Mg sebesar 2,19 \%, C/N Ratio sebesar 22,40 \%, dan Kadar Air sebesar 132,42 \%. Kompos KOTAKPLUS dapat memperbaiki sifat kimia tanah ultisol dengan dosis perlakuan yang terbaik adalah pada perlakuan D (KOTAKPLUS 30 ton/ha) dengan peningkatan nilai pH 0,70, C-Organik sebesar 2,14 \%, P sebesar 99,13 ppm, Ca sebesar 0,99 me/100 g tanah, dan Al-dd mengalami penurunan sampai tidak terukur.
\end{abstract}

Keywords : Empty Fruit Bunch, KOTAKPLUS, Ultisol, Compost.

\begin{abstract}
ABTRACT
This study aims to determine the nutrient content of oil palm empty fruit bunches compost plus (KOTAKPLUS). and the dosage of oil palm plus (KOTACPLUS) empty fruit bunch compost to improve soil chemical properties in ultisol soil. The study was conducted for seven months, starting in the first phase in February 2018, namely making oil palm plus (KOTAKPLUS) empty bunches compost and TKKS compost only. Then in the Second phase it starts in April 2018, which is the incubation time of compost. Data obtained from the treatments tested were taken based on the random sampling method. The incubation period of KOTAKPLUS compost consists of five levels of treatment and three replications, namely: $A=$ Without Treatment (Control), $B=$ KOTAKPLUS 10 tons ha-1, $C=$ KOTAKPLUS 20 tons ha-1, D = KOTAKPLUS 30 tons ha-1, and $E=$ OPEFB Compost only. Based on the results of research and analysis from the laboratory that has been carried out it can be concluded that KOTAKPLUS compost has a pH value of 10.1, C-Organic $21.06 \%, \mathrm{~N}$ of $0.94 \%, \mathrm{P}$ of $2.19 \%, \mathrm{~K}$ of 2, 94\%, Ca at $6.24 \%$, $\mathrm{Mg}$ at 2.19\%, C / N Ratio at 22.40\%, and Water Content at 132.42\%. Compost KOTAKPLUS can improve the chemical properties of ultisol soil with the best treatment dose is in treatment $D$ (KOTAKPLUS 30 tons / ha) with an increase in $\mathrm{pH}$ value of 0.70, C-Organic by 2.14\%, P at $99.13 \mathrm{ppm}$, Ca for $0.99 \mathrm{me} / 100 \mathrm{~g}$ of land, and Al-dd has decreased to unmeasurable.
\end{abstract}


Keywords: Empty Fruit Bunch, KOTAKPLUS, Ultisol, Compost.

Diterima : 17 Maret 2019, disetujui 25 Mei 2019

\section{PENDAHULUAN}

Provinsi Riau merupakan provinsi yang berada di pulau Sumatera yang memiliki 10 Kabupaten yang salah satunya adalah Kabupaten Kuantan Singingi (Kuansing). Kondisi tanah Kabupaten Kuansing didominasi oleh dataran tuf masam $31.80 \%$, dengan kemasaman tanah 4.7-5. Pada tahun 2013 Dinas Tnaman Pangan melaporkan bahwa klasifikasi tanah di Kabupaten Kuansing termasuk ordo ultisol. Hakim (2006) menjelaskan bahwa ciri-ciri tanah ultisol mengandung bahan organic yang rendah, $\mathrm{pH}$ rendah, sedikit mengandung unsur hara makro, defisiensi $\mathrm{P}$, dan adanya $\mathrm{Al}$ yang bersifat racun.

Kabupaten Kuantan Singingi adalah salah satu sentra penghasil komoditi perkebunan kelapa sawit, yang setiap bulannya akan menghasilkan limbah kelapa sawit yang akan menjadi masalah terhadap lingkungan, diantara nya adalah tandan kosong kelapa sawit. Berbagai hal dalam mengatasi permasalahan kesuburan tanah pada tanah ultisol salah satunya adalah dengan penambahan bahan organik. Sumber bahan organic yang cukup tersedia di Kab Kuansing adalah Limbah tandan kosong ( Tankos) sawit, yang dapat digunakan sebagai kompos yang akan menambah kekurangan bahan organic pada tanah ultisol. BPS (2015) melaporkan bahwa di Kabupaten Kuansing terdapat 18 pabrik kelapa sawit (PKS). Salah satu limbah PKS adalah Tandan kosong, bila tankos ini tidak dikelola dengan baik maka akan menjadi masalah bagi lingkungan, Penanganan limbah tankos sangat diperlukan dengan menerapkan konsep system pertanian berkelanjutan.

Tandan kosong kelapa sawit atau Empty Fruit Bunch (EFB), tankos ini dihasilkan dari pengolahan tandan buah segar menjadi minyak sawit kasar, dan minyak inti, sisanya adalah limbah dalam bentuk tankos dan cangkang (Darmosarkoro dan Winarna, 2007).

Pengomposan tankos merupakan salah satu upaya untuk mengurangi limbah PKS. Kompos tankos yang dihasilkan digunakan untuk menambah bahan organic yang dibutuhkan tanah ultisol agar dapat diberdayakan dalam proses budidaya tanaman. Okalia, Nopsagiarti, dan Ezward (2018), melaporkan bahwa ukuran kompos tankos yang baik adalah $<10 \mathrm{~cm}$, yang dikomposkan selama 3 bulan dengan menggunakan Trichoderma.

Sarwono (2008) melaporkan bahwa penggunaan kompos tankos dapat mengurangi pemakaian pupuk anorganik samapai $60 \%$. Lahirsin, Minwal, dan Gusmiatun (2017) melaporkan bahwa kompos tankos dosis 450 gram yang dicampur dengan 2 gram Urea menghasilkan pertumbuhan bibit kelapa sawit terbaik di pre nursery. Amri, Armaini, dan Purba (2018), menjelaskan bahawa kombinasi antara kompos tankos dan dolomit memperlihatkan pertumbuhan vegetative dan pertumbuhan akar bibit sawit di main nursery menjadi lebih baik.

Pengomposan dengan menggunakan EM4 yang dikombinasikan dengan waktu pemeraman bahan organik menghasilkan $6.79 \%$ N, 3.04\% P, dan 8.08\% (Toiby, Rahmadhani, dan Oksana, 2017). Wijana, dan Raka (2015) tankos dapat menggantikan peran top soil yang digunakan untuk pembibitan pre nursery, dan untuk menghasilkan bibit yang vigor digunakan perbandingan tankos 3 bagian, top soil satu bagian dan pasir satu 
bagian yang dikombinasikan dengan 4 gram Urea. Kompos tankos sawit yang digunakan untuk budidaya tanaman padi dapat meningkatkan $\mathrm{pH}$ tanah menjadi lebih baik, dan berpengaruh nyata terhadap jumlah klorofil (Hayat dan Andayani, 2014).

Limbah pengolahan sawit berupa tankos yang digunakan sebagai kompos akan menjawab permasalahan akibat menumpuknya tandan kosong kelapa sawit di pabrik, selain

\section{METODE PENELITIAN}

Lokasi penelitian adalah Balai Benih Induk (BBI) Sungai Rumbio Kabupaten Kuantan Singingi. Analisis sampel kedua kompos dan tanah dianalisis di Laboratorium Kimia Tanah Universitas Andalas Padang. Waktu yang digunakan untuk penelitian ini adalah tujuh bulan dimulai dari bulan Februari sampai dengan bulan Agustus 2018. Penelitian ini dilakukan dua tahap yaitu, tahap pertama pembuatan kompos yang terdiri dari Kompos Tandan Kosong Kelapa Sawit Plus (KOTAKPLUS), dan Kompos TKKS saja. Kemudian pada tahap kedua melakukan inkubasi KOTAKPLUS pada tanah Ultisol di BBI Sungai Rumbio Koto Kari Kabupaten Kuantan Singingi.

Bahan yang digunakan dalam penelitian ini adalah tandan Kosong Kelapa Sawit yang berasal dari pabrik pengolahan kelapa sawit PT. Usaha Kita Makmur desa Jake Kecamatan Kuantan Tengah, EM-4, Dolomite.

Random Sampling dipilih untuk menentukan sampel yang akan menjadi sumber data.. Kemudian data yang didapat dari beberapa perlakuan yang dilakukan dilapangan kemudian data dianalisa untuk mendapatkan data kuantitatif. Masa inkubasi kompos dilakukan selama 10 hari diuji dalam 5 taraf perlakuan dengan tiga kali ulangan, perlakuan yang dimaksud adalah: $\mathrm{A}=$ Kontrol (Tanpa Perlakuan), B = KOTAKPLUS 10 Ton itu dapat memberikan tambahan keuntungan dari penjualan kompos dan mengurangi biaya penggunaan pupuk anorganik (Darmosarkoro dan Winarna, 2007). Tujuan penelitian adalah untuk menetahui komposisi kimia yang terkandung di dalam kompos tankos, dan untuk mendapatkan dosis tankos yang terbaik yang dapat memperbaiki sifat kimia tanah Ultisol

ha $^{-1}, \mathrm{C}=$ KOTAKPLUS 20 Ton $\mathrm{ha}^{-1}, \mathrm{D}=$ KOTAKPLUS 30 Ton $\mathrm{ha}^{-1}, \mathrm{E}=$ Kompos TKKS 20 Ton ha ${ }^{-1}$.

\section{Analisis Data}

Analisis data menggunakan Analisis Statisitik secara sederhana, yaitu menjumlahkan dan merata-ratakan hasil pengukuran sifat kimia tanah tanah pada masing-masing perlakuan pada setiap ulangan.

Rumus Umum : $\hat{y}=\frac{\sum y}{n}$

Dimana : $\hat{y}=$ Rata-rata, $\sum y=$ Jumlah, dan $\mathrm{n}=$ jumlah ulangan. $\hat{\mathrm{y}}$

\section{Pelaksanaan Penelitian}

Pembuatan kompos pada penelitian ini masing-masing dibuat dengan bahan sebanyak $30 \mathrm{~kg}$ kompos, maka untuk kompos tandan kosong kelapa sawit saja disediakan bahan tandan kosong kelapa sawit kering 100\% (30 $\mathrm{kg}$ ). Kemudian untuk bahan-bahan yang digunakan untuk pembuatan $30 \mathrm{~kg}$ KOTAKPLUS adalah tandan kosong kelapa sawit (yang telah dicacah dengan menggunakan parang pencacah) $75 \%(22,5$ $\mathrm{kg})$, kotoran ayam kering $15 \%(4,5 \mathrm{~kg})$, dan untuk mempercepat proses dekomposisi kedua jenis kompos diberi kapur $10 \%$ dari berat total bahan kompos yaitu $3 \mathrm{~kg}$ kapur dolomit, kemudian diberi EM4 0,1\% (100 $\mathrm{ml}$ per $30 \mathrm{~kg}$ bahan kompos). Kemudian 
ditutup dengan terpal dan pembalikan kompos dilakukan seminggu sekali selama lebih kurang 3 bulan. Bedengan atau plot percobaan yang telah diberi label yaitu pada label A, B, C, D, dan E. Kemudian dilakukan pemberian perlakuan kompos KOTAKPLUS pada petak percobaan A tidak diberikan masukan apapun, $\mathrm{B}$ dengan dosis 750 gram plot $^{-1}$, C dengan dosis 1500 gram plot $^{-1}$, dan $\mathrm{D}$ dengan dosis 2250 gram plot $^{-1}$. Perlakuan E diberi kompos tandan kosong kelapa sawit saja dengan dosis 1500 gram plot $^{-1}$. Kompos disebarkan merata ke permukaan tanah, selanjutnya diaduk rata, dan dibiarkan selama 10 hari.

Analisis tanah dilakukan dua kali yaitu analisis tanah awal dan setelah 10 hari masa inkubasi dengan pemberian pupuk kompos KOTAKPLUS. Analisis Tanah Awal dapat dilihat pada tabel 1 .

Tabel . Hasil Analisis Tanah Awal

\begin{tabular}{cc}
\hline Jenis Analisa & Hasil \\
\hline $\mathrm{pH}$ & 5,45 \\
$\mathrm{~N}(\%)$ & 0,31 \\
$\mathrm{P}(\mathrm{ppm})$ & 2,27 \\
$\mathrm{C}-$ Organik $(\%)$ & 1,42 \\
$\mathrm{~K}(\mathrm{me} / 100 \mathrm{~g})$ & 0,98 \\
$\mathrm{Ca}(\mathrm{me} / 100 \mathrm{~g})$ & 1,47 \\
$\mathrm{Mg}(\mathrm{me} / 100 \mathrm{~g})$ & 1,42 \\
$\mathrm{Al}-\mathrm{dd}(\mathrm{me} / 100 \mathrm{~g})$ & 1,2 \\
\hline
\end{tabular}

\section{HASIL DAN PEMBAHASAN}

Hasil Sifat Kimia Kompos KOTAKPLUS Universitas Andalas Padang. Komposisi kimia dan Kompos TKKS saja

kompos tankos ditampilkan pada tabel.2

Analisis kedua kompos ini telah dilakukan di Laboratorium Kimia Tanah

Tabel 2. Hasil analisis kandungan unsur hara kompos KOTAKPLUS dan kompos TKKS saja.

\begin{tabular}{ccc}
\hline Kandungan Unsur hara & Kompos KOTAKPLUS & Kompos TKKS saja \\
\hline $\mathrm{pH}$ & 10,1 & 9,41 \\
C-Organik & 21,06 & 14,19 \\
$\mathrm{~N}$ & 0,94 & 6,28 \\
$\mathrm{P}$ & 2,19 & 1,88 \\
$\mathrm{~K}$ & 2,94 & 2,51 \\
$\mathrm{Ca}$ & 6,24 & 5,04 \\
$\mathrm{Mg}$ & 2,19 & 1,61 \\
$\mathrm{C} / \mathrm{N}$ ratio & 22,40 & 2,26 \\
KA & 132,42 & 112,36 \\
\hline
\end{tabular}

Setelah Tandan Kosong Kelapa Sawit yang ditambahan dengan berbagai bahan lain yang menjadi pupuk kompos KOTAKPLUS selain $\mathrm{pH}$ nya meningkat, Kandungan C-
Organik nya juga tinggi dan dapat menambah kandungan unsur hara $\mathrm{P}$ dan $\mathrm{K}$ dalam bahan kompos KOTAKPLUS. Pada penelitian apabila dibandingkan dengan kandungan 
kompos TKKS saja kandungan C-organik nya hanya $14,19 \%$ dan pada kandungan kompos TKKS saja terkandung $\mathrm{N}$ yang tinggi yaitu $6,28 \%$. Sedangkan pada unsur hara yang lain kandungan pupuk kompos TKKS saja masih sangat rendah jika dibandingkan dengan pupuk kompos KOTAKPLUS yang sudah ditambahkan dengan bahan campuran lain yang banyak mengandung $\mathrm{P}$ adalah kotoran ayam. Sehingga hal ini bisa memberikan solusi pada tanah masam seperti tanah ultisol.

\section{Analisis Sifat Kimia Tanah Ultisol kemasaman pH dan Al-dd}

Hasil Analisis kimia tanah awal dan analisis setelah di inkubasi selama lebih kurang 10 hari dengan menggunakan pupuk kompos KOTAKPLUS dan kompos TKKS saja dapat dilihat pada tabel 3.

Tabel 3. Hasil Analisis pH pada tanah awal dan setelah masa inkubasi 10 hari.dengan pemberian pupuk kompos KOTAKPLUS.

\begin{tabular}{|c|c|c|}
\hline Perlakuan & $\mathrm{pH}$ & Al-dd (me $100 \mathrm{~g}^{-1}$ ) \\
\hline $\mathrm{A}=$ Kontrol (Tanpa Perlakuan) & $5,45 \mathrm{~m}$ & 1,2 \\
\hline $\mathrm{B}=$ KOTAKPLUS 10 Ton $^{-1}$ & $6,03 \mathrm{am}$ & TU \\
\hline $\mathrm{C}=$ KOTAKPLUS 20 Ton $^{-1}$ & $6,10 \mathrm{am}$ & TU \\
\hline $\mathrm{D}=$ KOTAKPLUS 30 Ton $^{-1}$ & $6,14 \mathrm{am}$ & TU \\
\hline $\mathrm{E}=$ Kompos TKKS 20 Ton $^{-1}$ & $6,01 \mathrm{am}$ & TU \\
\hline Tanah Awal & $5,45 \mathrm{~m}$ & 1,2 \\
\hline
\end{tabular}

Keterangan $: m=$ masam, $a m=$ agak masam, $T U=$ tidak terukur

Pada tabel 3 menunjukkan bahwa nilai $\mathrm{pH}$ tanah berada pada kriteria agak masam apabila diberikan pupuk kompos KOTAKPLUS pada dosis yang berbeda. Peningkatan $\mathrm{pH}$ yang tertinggi adalah pada perlakuan D yaitu dosis pupuk kompos KOTAKPLUS 30 ton/ha. Nilai $\mathrm{pH}$ tanah awal atau pada perlakuan Kontrol A mengalami peningkatan nilai $\mathrm{pH}$ yaitu sebesar 0,69 unit dari tanah awal sebelum diberi perlakuan kompos KOTAKPLUS. Hal ini sesuai dengan pendapat Hakim, (2006) dan Mukhlis et al, (2011) yang menyatakan $\mathrm{pH}$ tanah dapat meningkat dengan pemberian bahan organik.. Dalam penelitian ini peningkatan nilai $\mathrm{pH}$ tanah juga disebabkan karena pemberian kapur pada pembuatan kompos KOTAKPLUS selain juga diberikan kotoran ayam pada perlakuan B, C, D, dan E. Hal ini sejalan dengan pendapat Hardjowigeno (2010) bahwa kapur dapat mengendalikan kemasaman tanah dan meningkatkan nilai $\mathrm{pH}$ tanah. Kemudian nilai Al-dd pada tanah awal adalah 1,2 setelah diberikan pupuk kompos KOTAKPLUS maka nilai Al-dd menjadi tidak terukur pada setiap perlakuan B, C, D dan E. Menurut Hanafiah (2005) bahwa tanah ultisol Al merupakan unsur yang dominan yang menyebabkan tanaman mengalami keracunan $\mathrm{Al}$ dan kekurangan unsur $\mathrm{P}$ karena $\mathrm{Al}$ memfiksasi $\mathrm{P}$ kemudian membentuk Al-P.

\section{Kandungan C-Organik}

Pemberian berbagai dosis pupuk kompos KOTAKPLUS pada tanah ultisol pada kandungan C-organik. Masa inkubasi 10 hari dengan pemberian pupuk kompos KOTAKPLUS mengalami peningkatan nilai C-Organik yang berbeda pada setiap perlakuan dan termasuk kategori sedang berdasarkan kriteria penilaian sifat kimia tanah (LPT 1983) dapat dilihat pada tabel 4. 
Tabel 4. Hasil Analisis C-Organik pada tanah awal dan setelah masa inkubasi 10 hari.dengan pemberian pupuk kompos KOTAKPLUS.

\begin{tabular}{ccc}
\hline Perlakuan & C-Organik (\%) & Kriteria \\
\hline A $=$ Kontrol (Tanpa Perlakuan) & 1,42 & rendah \\
B = KOTAKPLUS 10 Ton $\mathrm{ha}^{-1}$ & 1,64 & rendah \\
C $=$ KOTAKPLUS 20 Ton ha & rendah \\
D $=$ KOTAKPLUS 30 Ton $\mathrm{ha}^{-1}$ & 1,77 & sedang \\
$\mathrm{E}=$ Kompos TKKS 20 Ton ha & & rendah \\
\hline Tanah Awal & 3,56 & rendah \\
\hline
\end{tabular}

Pada tabel 4. Menunjukkan bahwa kandungan C-Organik pada tanah awal sebelum masa inkubasi adalah 1,42 \% termasuk dalam kriteria rendah. Dengan pemberian kompos KOTAKPLUS dosis 30 ton $\mathrm{ha}^{-1}$ berhasil meningkatkan kandungan $\mathrm{C}$ Organik sebesar 3,56\%. Hal ini pupuk kompos KOTAKPLUS mampu meningkatkan 2,14\% C-organik pada tanah ultisol. Sedangkan pada perlakuan lain masih dalam kategori rendah yaitu, A tanpa perlakuan, B 10 ton/ha $1,64 \%$, C 20 ton ha ${ }^{-1}, 77 \%$ dan E Kompos TKKS saja hanya mampu meningkatkan $1,45 \%$ yaitu hanya mampu meningkatkan $0,03 \%$ dari tanah awal. Menurut Hakim (2006) penambahan bahan organic ke dalam tanah, selain dapat meningkatkan bahan organic di tanah tersebut juga dapat mempertahankan bahan organic yang sudah ada di tanah tersebut.

\section{Kandungan P dan Ca}

Berdasarkan hasil analisis kimia $\mathrm{P}$ dan Calsium tanah awal dan setelah masa inkubasi 10 hari dengan pemberian kompos KOTAKPLUS pada tabel 5.

Tabel 5. Hasil Analisis $\mathrm{P}$ dan Ca pada tanah awal dan setelah masa inkubasi 10 hari.dengan pemberian pupuk kompos KOTAKPLUS

\begin{tabular}{|c|c|c|}
\hline Perlakuan & P-tersedia (ppm) & Ca-dd (me/100g) \\
\hline $\mathrm{A}=$ Kontrol (Tanpa Perlakuan) & 2,27 rendah & 1,47 sangat rendah \\
\hline $\mathrm{B}=$ KOTAKPLUS 10 Ton ha ${ }^{-1}$ & 74,70 Sangat tinggi & 1,93 sangat rendah \\
\hline $\mathrm{C}=$ KOTAKPLUS 20 Ton $\mathrm{ha}^{-1}$ & 99,20 Sangat tinggi & 2,21 rendah \\
\hline $\mathrm{D}=$ KOTAKPLUS 30 Ton ha $^{-1}$ & 101,41 Sangat tinggi & 2,47 rendah \\
\hline $\mathrm{E}=$ Kompos TKKS 20 Ton ha $^{-1}$ & 66,17 Sangat tinggi & 2,12 rendah \\
\hline Tanah Awal & 2,27 rendah & 1,47 sangat rendah \\
\hline
\end{tabular}

Kandungan $\mathrm{P}$ mengalami peningkatan pada tanah ultisol yang telah mengalami masa inkubasi selama 10 hari dengan pemberian pupuk kompos KOTAKPLUS. Hal ini disebabkan karena kandungan $\mathrm{P}$ pada KOTAKPLUS sangat tinggi jika dibandingkan dengan kandungan $\mathrm{P}$ pada kompos TKKS saja. Dari hasil penelitian ini terlihat bahwa pemberian pupuk kompos KOTAKPLUS dapat memberikan sumbangan unsur hara $\mathrm{P}$ kedalam tanah. Sehingga unsur hara $\mathrm{P}$ menjadi tersedia dalam tanah dan mengalami peningkatan dari 2,27 ppm menjadi 101,41 ppm. Hal ini sejalan dengan pendapat Hanafiah (2005) P tersedia di dalam tanah bisa disebabkan karena adanya bahan organic di tanah tersebut, baik secara langsung ataupun dengan proses mineralisasi, atau dengan perlakuan yang diberikan sehingga dapat melepaskan $\mathrm{P}$ yang terfiksasi. 


\section{KESIMPULAN}

Pupuk Kompos Tandan Kosong Kelapa Sawit (KOTAKPLUS) kandungan Corganik cukup tinggi dan juga mengandung unsur hara $\mathrm{N}, \mathrm{P}$ dan $\mathrm{K}$ yang bisa meningkatkan kesuburan tanah ultisol yang memiliki ciri kimia sebagai berikut : $\mathrm{pH}$ sebesar 10,1, N sebesar 0,94\%, P sebesar 2,19\%, K sebesar 2,94\%, Ca sebesar 6,24\%, $\mathrm{Mg}$ sebesar 2,19\%, C-Organik sebesar 21,06\%, C/N Ratio 22,40, dan Kadar Air $132 \%$.

\section{UCAPAN TERIMAKASIH}

Alhamdulillah kami mengucapkan terimakasih kepada Direktorat Jenderal Penguatan Riset dan Pengembangan KEMENRISTEK DIKTI yang telah membiayai sepenuhnya penelitian dosen

\section{DAFTAR PUSTAKA}

Amri, A. I., Armaini, dan Purba, M. R. A. 2018. Medium Sub Soil Inceptisol Terhadap Bibit Kelapa Sawit ( Elaeis guineensis Jacq .) Di Pembibitan Utama. J. Agroteknologi, 8(2), 1-8.

Darmosarkoro, W. dan Winarna. 2007. Penggunaan TKS dan Kompos TKS untuk Meningkatkan Pertumbuhan dan Produksi Tanaman. Jurnal Lahan dan Pemupukan Kelapa Sawit Edisi 1. Pusat Penelitian Kelapa Sawit, C4:181-194.

Disbun. 2015. Data Produksi Padi, Jagung, dan Kedelai Provinsi Riau. Berita Resmi Statistik. Riau

Hakim, N. 2006. Pengelolaan Kesuburan Tanah Masam dengan Teknologi
Kompos Tandan Kosong Kelapa Sawit Plus (KOTAKPLUS) dapat memeperbaiki sifat kimia tanah ultisol dengan dosis perlakuan yang terbaik adalah pada perlakuan D (KOTAKPLUS 30 ton $\mathrm{ha}^{-1}$ ) dengan peningkatan nilai $\mathrm{pH}$ 0,70, C-Organik sebesar 2,14 \%, P sebesar 99,13 ppm, Ca sebesar 0,99 me/100 g tanah, dan Al-dd mengalami penurunan sampai tidak terukur.

pemula ini, Rektor UNIKS, LPPM UNIKS, Dekan Faperta UNIKS, Dinas Pertanian Kabupaten Kuansing, serta semua pihak yang telah banyak membantu dalam penelitian ini

Pengapuran Terpadu. Padang. Andalas University Press. 204 hal.

Hayat, E. S., dan Andayani, S. 2014. Pengelolaan Limbah Tandan Kosong Kelapa Sawit Dan Aplikasi Biomassa Chromolaena odorata Serta Sifat Tanah Sulfaquent. Jurnal Teknologi Pengelolaan Limbah, 17(2), 44-51.

Lahirsin, M., Minwal, dan Gusmiatun. 2017. Pemberian Pupuk Nitrogen Dan Kompos Tandan Kosong Kelapa Sawit Untuk Meningkatkan Pertumbuhan Bibit Kelapa Sawit (Elaeis guineensis Jacq) STADIA PRE NURSERY. J. Klorofil, XII(2), 73-77.

Okalia, D., Nopsagiarti, T., dan Ezward, C. 2018. Pengaruh Ukuran Cacahan 
Tandan Kosong Kelapa Sawit Terhadap Karakteristik Fisik Kompos Tritankos (Triko Tandan Kosong). Jurnal Agroqua, 16(2), 132-142.

Sarwono, E. 2008. Pemanfaatan Janjang Kosong Sebagai Subtitusi Pupuk Tanaman Kelapa Sawit. J. APLIKA, 8(1), 19-23.

Toiby, A. R., Rahmadhani, E., dan Oksana. 2017. Perubahan Sifat Kimia Tandan Kosong Kelapa Sawit Yang
Difermentasi Dengan Em4 Pada Dosis Dan Lama Pemeraman . J. Agroteknologi, $\quad 6(1), \quad$ 1-8. https://doi.org/10.24014/ja.v6i1.1370

Wijana, G., dan Raka, I. G. N. 2015. Pemanfaatan Tandan Kosong Kelapa Sawit dan Pupuk Nitrogen Sebagai Substitusi Top Soil terhadap Pertumbuhan Bibit Kelapa Sawit ( Elaeis Guineensis Jacq .) Periode Pre Nursery, 4(4), 264-273. 